\title{
st \\ "De humani corporis circus" de Gunther von Hagens
}

Regina André Rebollo

Desde 1996, o médico anatomista alemão Gunther von Hagens vem promovendo a exposição "Os mundos do corpo - exibição anatômica do homem real" ("Body worlds the anatomical exhibition of real human") no Japão, Alemanha, Áustria, Bélgica, Londres e Seul. O evento já foi visitado por pelo menos 8 milhões de pessoas e nele são apresentados 200 exemplares anatômicos (25 corpos e 175 partes) conservados a partir de uma nova técnica para a conservação de órgãos e estruturas do corpo humano, chamada por Hagens, seu idealizador, de plastinização (plastination).

Gunther von Hagens, doutor em medicina pelo Departamento de Anestésicos e Medicina de Emergência da Universidade de Heidelberg (1975), logo depois, teve sua fama ligada a essa técnica de plastinização, que ele desenvolveu em 1978, quando trabalhava no Instituto de Anatomia e Patologia da Universidade de Heidelberg. Desde 1996, curiosamente, é professor visitante da Escola de Medicina de Dalian, na China e diretor do Centro de Plastinização da Academia Médica Estadual de Bishkek, na República do Quirguistão. Autor de várias publicações, Hagens possui também uma empresa sediada em Heidelberg, a BIODUR ${ }^{\mathrm{TM}}$, que comercializa os equipamentos e os polímeros utilizados na técnica de plastinização e também um Instituto onde põe em prática o trabalho de conservação e fixação das peças anatômicas.

A plastinização consiste basicamente no seguinte: durante um processo a vácuo, exemplares biológicos são preenchidos por um polímero desenvolvido especialmente para esse fim. O tipo de polímero utilizado determina as propriedades mecânicas (flexibilidade e rigidez) e ópticas (transparência ou opacidade) da peça preservada. A plastinização tem a vantagem de ser uma técnica de conservação seca e inodora, mantendo o relevo natural das superfícies e a peça idêntica ao seu estado antes da fixação, permitindo o exame macro e microscópico com grande acuidade visual. A plastinização substitui os fluidos corporais e a gordura com polímeros reativos, tais como silicone, borracha, resinas de epóxi ou poliéster. Na primeira fase do processo, solventes substituem gradualmente os fluidos com um banho de solvente gelado ("substituição por congelamento"); em seguida, a peça desidratada é colocada num banho de imersão de solvente na temperatura ambiente, para a retirada da gordura. A peça, desidratada e sem gordura, é colocada numa solução de polímero. O solvente é, então, fervido a vácuo e continua- 
mente extraído. O solvente evaporado cria um vazio dentro da peça que será gradualmente preenchido pelo polímero. Após o processo (chamado de "impregnação forçada"), a peça é curada com gás, luz, ou calor, dependendo do tipo de polímero utilizado.

A técnica de plastinização é também feita em fatias milimétricas do corpo, de suas partes, tecidos e órgãos. Ela consiste basicamente no seguinte: partes do corpo ou o corpo inteiro, em geral congelados, são cortados ou serrados (no caso dos ossos) em fatias de 2 a $8 \mathrm{~mm}$ de espessura. As fatias são em seguida colocadas numa malha de fio metálico, onde serão desidratadas, "desengorduradas" e saturadas a vácuo com polímeros, como descrito acima. Depois, são conservadas entre duas películas ou fundidas com polímeros adicionais, num recipiente plano composto de lâminas de vidro que lhes darão uma superfície fina e lisa. Essa técnica permite a visualização transversal anatômica do corpo com um detalhamento jamais observado.

Hagens e sua equipe levam 1500 horas para preparar as peças inteiras e as vendem para escolas de medicina, museus, instituições e pessoas interessadas por no mínimo 15.000 libras esterlinas.

Todas as peças apresentadas na exposição "Os mundos do corpo" foram preparadas dessa maneira e elas pertenceram a pessoas que em vida doaram seus corpos para a ciência médica. No Instituto para a Plastinização de Hagens em Heidelberg, existe um programa de doação de corpos. O anatomista afirma que 4.500 pessoas já estão inscritas. Embora sustente que os corpos foram obtidos legalmente, em 1999, uma revista alemã publicou uma reportagem que o acusava de ter, no Instituto de Plastinização de Heidelberg, 56 corpos de indigentes e pacientes siberianos com problemas mentais. De fato, Hagens possui um contrato com o Instituto de Anatomia da Universidade de Novossibirsk, autorizando-o a recolher os corpos não reclamados de moradores de asilos e instituições assistenciais.

No material de divulgação da exposição "Os mundos do corpo", afirma-se que o objetivo maior do evento é possibilitar uma visão única do corpo humano saudável e do corpo humano doente apresentando os órgãos e as partes de acordo com temas específicos, tais como o sistema nervoso ("the body electric"), a respiração ("breath by breath"), o sistema cardiovascular ("beat by beat"), e a estrutura óssea ("strong stuff"), entre outros. Aintenção é aquela que vem sendo praticada nas escolas médicas desde o século XVI, ensinar a função das partes no sistema específico e mostrar as suas doenças típicas, bem como expor as estruturas anatômicas individuais.

A exposição, como é comum na Europa, conta ainda com uma loja na qual são vendidos artefatos como relógios, pesos de mesa, "mousepads", jogos infantis, cartões postais e camisetas, especialmente estampados com os objetos exibidos no evento.

Hagens organiza os corpos plastinizados em posições dinâmicas que, embora cotidianas, produzem um efeito final bastante bizarro. O conjunto reúne 25 corpos, 
“De humani gorporis girgus" de Gunther von Hagens

entre eles um jogador de basquete, um jogador de xadrez, um cavaleiro montado em seu cavalo, este último também plastinizado, uma mulher grávida cujo ventre aberto permite a visão de um feto de oito meses, e um homem carregando a sua própria pele. As peças foram dissecadas, abertas, divididas e "desfolhadas" em camadas, ora dandose ênfase aos músculos, ora à pele, ora ao sistema circulatório, ora ao sistema nervoso. A forma de apresentação lembra aquela de Vesálio e dos anatomistas dos séculos XVI e XVII, época do grande reflorescimento da investigação anatômica, quando as pranchas anatômicas mostravam a estrutura nervosa ou muscular de figuras humanas que, em posições elegantes, posavam tendo como pano de fundo belas paisagens campestres de Pádua ou Florença.

A visão é de fato única. O "corpo humano real” que se observa é completamente diferente daquele que vemos usualmente. Cada exemplar preparado parece pertencer a um protótipo humano que se diferencia muito da imagem que temos de nós mesmos.

As reações ao evento são as mais diversas. De uma maneira geral, é sucesso de público e motivo de inquietação para aqueles que se ocupam das questões éticas e científicas e que não poupam críticas ao caráter sensacionalista e de showbusiness do evento. O site da exposição relata que a Universidade de Kassel, na Alemanha, fez um estudo sobre a reação do público concluindo que nenhuma exposição anterior suscitara um debate tão intenso. A pesquisa foi desenvolvida por Ernest D. Lantermann, professor do Instituto de Psicologia, e suas principais conclusões foram as seguintes: a maior parte do público europeu considerou a exposição muito boa ou boa; aprovou a apresentação dos corpos e das partes plastinizadas, considerando-as bastante apropriadas para o aprendizado; 83\% afirmaram ter obtido um grande conhecimento sobre o corpo humano; $47 \%$ disseram que a exposição lhes ensinou sobre a vida e a morte; $80 \%$ sentiram profunda reverência pela maravilha dos corpos; 60\% saíram da exposição decididos a levar uma vida mais saudável e 33\% afirmaram que passaram a gostar mais do corpo humano do que antes. Estes últimos disseram que se empenhariam para deixar de beber álcool e fumar.

\section{A DEMONSTRAÇÃo ANATÔMiGA EM LoNDRES}

Em 20 de novembro de 2002, desafiando as autoridades inglesas, Hagens promove uma autópsia pública numa antiga cervejaria nos arredores de Londres. Tudo começou quando a exposição "Os mundos do corpo", que já tivera, em março de 2002, dificuldades iniciais para obter autorização do Departamento de Saúde Inglês, não obteve permissão para ser prorrogada, após ter sido visitada por $55^{\circ}$ mil pessoas. 
Hagens promoveu a autópsia diante de uma platéia de 500 pessoas e de câmeras de TV da emissora Chanel 4, que colocou no ar uma versão editada do evento. A pedido da polícia, dois agentes da Scotland Yard e dois professores de anatomia estavam presentes. $\mathrm{O}$ corpo necropsiado pertencera a um senhor de 72 anos, fumante e consumidor de álcool, segundo Hagens. Vestindo o tradicional avental cirúrgico azul e um chapéu de feltro preto, sua marca registrada, Hagens abriu a performance sugerindo ao público que desviasse o olhar, se necessário. Em seguida, cortou o peito do cadáver e abriu o esterno com as duas mãos. Durante as três horas seguintes retirou todos os órgãos, separando o que sobrou do corpo de uma pilha de órgãos amontoados na bandeja. Cada passo do procedimento foi descrito e explicado ao público, pois o objetivo inicial era "abrir o corpo real humano na presença de leigos estabelecendo a causa mortis e as anormalidades". Quando todos os órgãos foram retirados, Hagens os colocou novamente no lugar e costurou a abertura feita no tórax. Uma cópia da tela de Rembrandt, "Aula de anatomia do Dr. Nicholaes Tulp", de 1632, foi estrategicamente pendurada na parede, atrás da mesa metálica onde o corpo foi colocado, diante da platéia.

A autópsia pública de Hagens deu-se após 170 anos da proibição desse tipo de evento pelas autoridades do Reino Unido, no intuito de impedir o roubo de cadáveres. No século XVI, as necropsias públicas tornaram-se muito populares na Europa, quando a Igreja Católica autorizou a dissecação para ajudar na compreensão do "milagre da criação". Em 1565, a rainha Elizabeth I forneceu ao Colégio Médico Londrino uma licença real para dissecar corpos de criminosos condenados. Desde então, a atividade de investigação anatômica será também praticada fora das universidades e escolas médicas, transformando-se em objeto de interesse e curiosidade para um público leigo.

Contra aqueles que o criticam, Hagens argumenta que sua atividade não deve ser condenada, pois serviria ao enlightenment geral e chega a traçar paralelos com o período moderno. Ele afirma que é um continuador da tradição anatômica de Galeno e Vesálio e de uma época na qual as demonstrações públicas eram promovidas em teatros anatômicos. Para ele, lamentavelmente, tais demonstrações estariam hoje confinadas a uma elite médica, privando o público leigo "do espetáculo e da maravilha do corpo humano". Hagens acredita que o seu papel é o de lutar pela "democratização da anatomia”. Diante de tais fatos farei alguns comentários que me parecem pertinentes.

Em primeiro lugar, a técnica de plastinização desenvolvida por Hagens é uma inovação no campo técnico e por enquanto não trouxe novas informações significativas na área do conhecimento médico e científico. É sabido que o conhecimento anatômico, pelo menos a macroanatomia humana, é um conhecimento descritivo que serve mais ao ensino e à formação do que à aquisição de novos conhecimentos. Esse não é o caso da anatomia microscópica e da anatomia comparada, por exemplo. $\mathrm{O}$ espetáculo de Hagens deve, portanto, na minha opinião, ser analisado à luz do desenvol- 
“De humani gorporis girgus" de Gunther von Hagens

vimento técnico e não científico, como se poderia pensar. Aqui, a técnica está a serviço da divulgação científica. Quando Hagens afirma que a exposição contribui para o enlightenment geral é preciso dizer que o que ele faz localiza-se no campo da divulgação científica e não no da produção do conhecimento. Assim, os valores e julgamentos relacionados com o evento não podem ser deduzidos dos valores da ciência e dos cientistas, que nem sempre coincidem. Hagens não é um cientista e nem se comporta enquanto tal. Por isso, ao se comparar aos grandes anatomistas do passado, como Galeno e Vesálio, Hagens ignora que tais anatomistas estavam estabelecendo um novo método de observação e sistematização do corpo humano, que trouxe ao conhecimento médico e científico novos resultados. Talvez Hagens devesse apenas dizer que muitas das suas figuras humanas plastinizadas tiveram como inspiração o trabalho e as reproduções de Vesálio, Juan Valverde, Leonardo da Vinci, Fabrício de Acquapendente, Júlio Cassério, Johan Remmelin e Albinus, por exemplo.

Em segundo lugar, as críticas ao caráter sensacionalista e de showbusiness do evento são descabidas. É um espetáculo mesmo, onde Hagens é mentor, diretor e produtor. Cabe lembrar que o anatomista está reunindo uma pequena fortuna com seus eventos e performances. O problema se coloca quando lembramos que os objetos da exposição são seres humanos. Do ponto de vista ético, na minha opinião, a questão mais importante a ser considerada é saber como os corpos e suas partes foram adquiridos. A forma, o arranjo e o contexto das peças são irrelevantes, uma vez que se trata de expor o corpo assim como ele é. Ou melhor, assim como a tradição livresca e museológica o representa nos últimos 500 anos. Uma rápida consulta aos tratados de anatomia descritiva e artística mostra que as peças de Hagens são tão magníficas, e ao mesmo tempo horripilantes, quanto aquelas representadas por esses manuais.

Com relação à necropsia do dia 20 de novembro, é preciso perguntar por que a Associação Médica Britânica considerou o evento degradante e desrespeitoso, desejando que a experiência não se repetisse. Estaria a instituição preocupada com o crescente interesse mórbido pelo corpo humano por parte de pessoas exógenas ao meio acadêmico e científico? Não sou especialista no assunto, mas nota-se, na primeira metade do século que acaba de terminar, um reavivamento do interesse pelo corpo humano nos movimentos artísticos e culturais. Entre os artistas ingleses, o caso mais interessante é Anthony Noel Kelly, condenado a nove meses de prisão por ter utilizado cadáveres roubados para fazer moldes de esculturas. Kelly era açougueiro, antes de optar pelo mundo das artes; Damien Hisrt, por sua vez, corta animais em pedaços e os coloca dentro de um tanque com formol; Mark Quinn cria esculturas de si mesmo preenchidas com o próprio sangue. $\mathrm{O}$ fenômeno não se restringe às galerias de arte. Um dos últimos videoclips do popstar inglês, Robbie Williams, apresenta-o colocando em prática uma nova forma de sedução: uma vez que vestido é completamente ignorado pelas 
garotas, faz um striptease de si mesmo, retirando a pele e os músculos, que são atirados à platéia, expondo órgãos e vasos, desfolhando-se até chegar aos ossos e se transformar num alegre esqueleto dançante. Com isso, obtém uma mórbida atenção. Por sinal, assim como Hagens. Caberia perguntar por que a exposição "Corpos espetaculares: a arte e a ciência do corpo humano de Leonardo até hoje" "Spectacular bodies: the art and science of the human body from Leonardo to now"), apresentada na Hayward Gallery (Londres) no inverno de 2000, não sofreu as críticas que Hagens está recebendo. Contrariamente, foi bastante elogiada. A resposta pode ser a chave para a compreensão do "fenômeno Hagens". A exposição na Hayward Gallery procurou mostrar as representações artísticas e médicas do corpo e da face nos últimos 500 anos acompanhadas de trabalhos de oito artistas contemporâneos que dão uma nova perspectiva ao tema. A exposição foi acompanhada de eventos e discussões acadêmicas promovidas por especialistas em história da medicina, conferindo-lhe um caráter que foi muito além do puro espetáculo. A interpretação histórica e filosófica do passado da anatomia difere significativamente da perspectiva "futurista" de Hagens. Um dos seus projetos mais recentes merece um comentário à parte, pois elucida a natureza de seus trabalhos. $\mathrm{O}$ anatomista está solicitando a pacientes terminais que doem seus corpos após a morte para que sejam dissecados e reconstruídos como um "super-homem", cada passo do procedimento filmado por câmeras de TV. O objetivo do projeto é "identificar e corrigir as imperfeições do design da anatomia humana”. O corpo será redesenhado por Hagens e uma equipe de biólogos, cirurgiões e engenheiros mecânicos, que darão uma forma "mais aperfeiçoada" à anatomia do homem. Algumas idéias já definidas incluem aumentar o número de costelas para proteger melhor os órgãos internos; criar joelhos que se dobrem para trás, diminuindo o desgaste das juntas; reposicionar a traquéia e o esôfago para impedir que a comida desça pela traquéia-artéria por engano; duplicar o coração ou reconstruir a artéria coronária e fabricar um pênis retrátil. Para Hagens, essa seria uma "maneira interessante de testar aquilo que a engenharia genética poderá fazer no futuro". A perspectiva de Hagens valoriza claramente a tecnologia sobre toda e qualquer outra forma de ação no mundo e suas implicações morais.

Para finalizar, embora as reações aos eventos citados acima tenham sido as mais diversas, o sucesso de público não pode ser ignorado. Hagens recupera o espírito da ciência-espetáculo, tão em voga nas cortes européias nos séculos XVI a XVIII. É sabido que, nessa época, a ciência e os cientistas são um espetáculo à parte, entretendo a nobreza e a sua entourage com as "maravilhas científicas" recém descobertas, a pesquisa anatômica entre elas. Uma crescente curiosidade e atração pelas "coisas novas" fará surgir a cultura do colecionador particular e conseqüentemente um mercado de curiosidades alimentado por nobres e eruditos. Surgem, então, os museus, os jardins botânicos, as ménageries ou coleções de animais raros, vindos da América, da África e das 
Índias. Os espécimens naturais e humanos serviam de decoração ritual nas grandes cerimônias. Foi dessa forma que, em 1550, Henrique II entrou na cidade de Rouen atravessando um cenário que reconstituía o Brasil, exatamente como hoje são feitas as alegorias carnavalescas. Nessa época, médicos, cirurgiões e boticários reais ocupavam também o papel de comentadores oficiais da "diversidade da natureza". O caso mais interessante é o de Ambroise Parré, primeiro cirurgião de Charles IX. Em Sobre os monstros e os prodígios (Des monstres et prodiges) publicado em $157^{3}$, Paré, apoiando-se nas descrições de André Thevet, na época "garde du cabinet des curiositez", discorre sobre o novo mundo e as curiosidades médicas e naturais. De Tours, em 1569, um cirurgião envia-lhe um cadáver seco e dissecado de uma criança recém-nascida com dois corpos e uma cabeça. É obvio que a coleção reunida por Paré não desmerece o seu trabalho científico, pelo contrário, ela o enriquece. Da mesma maneira, não estou aqui criticando a técnica de plastinização em si, que pode ser muito útil ao ensino e à divulgação do conhecimento médico anatômico. Se objeções devem ser feitas a Hagens, uma delas é a de explorar apenas as conseqüências comerciais da técnica. Além disso, ao pretender que a técnica tenha o mesmo estatuto da ciência e ao confundir ciência com divulgação científica, Hagens perde a oportunidade de associar a sua empreitada uma reflexão histórica e filosófica mais profunda, tal como aquela explorada pela exposição feita na Hayward Gallery.

(As informações colhidas para a elaboração desta nota crítica foram retiradas do site oficial da exposição "Body worlds - the anatomical exhibition of real human" [www.koerperwelten.de/en] e [www.bodyworlds.com]; Os jornais "The Gardian Unlimited"; "BBC News Online" e "Le Monde” também foram consultados.)

\section{Regina André Rebollo}

Pesquisadora do Projeto Temático "Estudos de filosofia

e história da ciência" da FAPESP, pós-doutoranda do Departamento de Filosofia da Universidade de São Paulo. haniger@usp.br 